\title{
The combined effects of blue light and dilution rate on lipid class and fatty acid composition of Tisochrysis lutea
}

\author{
Marchetti Julie ${ }^{1}$, Da Costa Fiz ${ }^{2}$, Bougaran Gaël ${ }^{1}$, Quéré Claudie ${ }^{3}$, Soudant Philippe ${ }^{4}$, Robert René ${ }^{5,{ }^{*}}$ \\ ${ }^{1}$ Laboratoire Physiologie et Biotechnologies des AlguesIFREMERNantes cedex 3, France \\ ${ }^{2}$ Oceano Fresco Lda., Edifício Mira CenterMira, Portugal \\ ${ }^{3}$ Ifremer, Laboratoire des Sciences de l'Environnement Marin (UMR 6539, LEMAR)Plouzané, France \\ ${ }_{5}^{4}$ Laboratoire des Sciences de l'Environnement Marin (UMR 6539, LEMAR)IUEM/UBOPlouzané, France \\ ${ }^{5}$ Ifremer, Unité LittoralCentre BretagnePlouzané, France \\ *Corresponding author : René Robert, email address : rene.robert@ifremer.fr
}

\begin{abstract}
:
The lipid class and the fatty acid compositions of microalgae highly influence bivalve larval and postlarval development. Light is an essential environmental factor for microalgal culture, and quantity and quality of light may induce changes in the biochemical composition of the algae. The objective of this study was to investigate the effect of light spectrum (blue vs. white light) on lipid class and fatty acid compositions of Tisochrysis lutea cultured in a chemostat. Two different dilution rates (D) were assayed for each light spectrum: 0.2 and 0.7 day-1. Triacylglycerol (TAG), sterol, and hydrocarbon (HC) content increased sharply at low $\mathrm{D}$. The proportion of alkenones was significantly reduced under blue light. Polyunsaturated fatty acids (PUFA), and particularly n-3 PUFA, content in phospholipids (PL) increased under blue light compared to white light at low D. Thus, blue light raised 22:6(n-3) levels in total lipids of $T$. lutea at low $\mathrm{D}$. The cultivation of $T$. lutea in a chemostat at low $\mathrm{D}$ under blue light may improve nutritional value as feed for bivalve larvae by modifying the PUFA profile, especially increasing 22:6(n3).
\end{abstract}

Keywords : Tisochrysis lutea, Blue light, Dilution rate, Lipid classes, Fatty acids, Chemostat 


\section{Introduction}

Commercial applications of microalgae have expanded in recent years to include the production of a wide range of molecules as nutritional supplements, antioxidants, cosmetics, natural dyes, and polyunsaturated fatty acids (PUFA) (reviewed in Spolaore et al. (2006)) or biodiesel (Schenk et al. 2008). Live microalgal supply is essential in shellfish aquaculture as no alternative for total substitution of live diets has been found yet. Moreover, specific nutritional needs of each shellfish species still are incompletely known. Accordingly, feeds are supplied as mixed-algal diets to provide an estimated balanced diet thought to meet nutritional requirements. Manipulation of algae may be a relative simple way to alter feed composition without culturing several species, allowing the algal culturist to focus on algal species that are known to have high ingestion and digestion rates by bivalves (Marshall et al. 2010) and that are easy to culture.

Microalgal biochemical composition, and specifically lipid content and profile, can change during culture aging (Fernández-Reiriz et al. 1989; Alonso et al. 2000). For example, protein accumulation is enhanced during Isochrysis aff. galbana exponential phase; whereas, carbohydrates and lipids are mainly stored during the stationary phase (Brown et al. 1993).

Microalgae can be grown in a physiological steady state under constant environmental conditions. In this steady state, growth occurs at a constant specific growth rate and all culture parameters remain constant. Microalgae growing in chemostats reach a steady state due to a negative feedback between growth rate and nutrient consumption. Due to the self-regulation, the steady state is stable. This enables the experimenter to control the specific growth rate of the microorganisms by changing the speed of the pump feeding fresh medium into the vessel. Accordingly, harvesting at a specific growth phase and manipulating culture conditions, such as nutrient supply, may allow the orientation of lipid composition for specific purposes (Dunstan et al. 1993). The benefits for the industry are undeniable because microalgal composition can be modulated/orientated by changing dilution rate and manipulation nutrient supply.

Tisochrysis lutea (formely Isochrysis affinis galbana or T-Iso: Bendif et al. 2013) is a microalga used widely as live food in bivalve hatcheries because of an advantageous fatty acid profile and relative ease of culture (Ewart and Pruder 1981; Napolitano et al. 1990). Biochemical and fatty acid composition of a given species of phytoplankton can be modified under different growing conditions, such as 
nutrients, light intensity and spectrum of light, and temperature (Mortensen et al. 1988; Sukenik and Wahnon 1991), according to the growth phases of the algae (harvesting stage) (Fernández-Reiriz et al. 1989; Brown et al. 1993) and also depending on the culture system (Ponis et al. 2006). Among these variables, light is an essential ingredient for microalgal culture (Marchetti et al. 2012). Indeed, microalgal metabolism and growth can be modified not only by light quantity (irradiance) but also by light quality (light spectrum) (Gostan et al. 1986; Wynne and Rhee 1986; Rivkin 1989; Marchetti et al. 2013). Marchetti and co-workers (2013) showed that T. lutea growth was similar at both light spectra (blue and white); whereas, protein synthesis increased under blue light at the expense of carbon metabolism. Light spectrum (quality) did not, however, modulate total lipid content (Marchetti et al. 2013).

Lipid class composition can be modified by environmental and culture conditions (Parrish 1987; Alonso et al. 2000); however, this area of research remains little developed. Some lipids have an energy storage role, such as triglycerides (Saoudi-Helis et al. 1994). Others may also be involved in the development of the photosynthetic system, such as glyceroglycolipids, which are important compounds in the thylakoid membrane, with a role in the photochemical reactions of photosynthesis (Bruce 1998).

Polyunsaturated fatty acids (PUFAs) are important nutrients in marine trophic webs. More precisely, omega-3 fatty acids eicosapentaenoic acid 20:5(n-3) (EPA) and docosahexaenoic acid 22:6(n3) (DHA) are essential for growth, development, and reduced mortality in most marine animals, particularly in fish (Reitan et al. 1994) and mollusc larvae (Langdon and Waldock 1981; Knauer et al. 1999; Aranda-Burgos et al. 2014) because these compounds are major membrane components (Hendriks et al. 2003) and possible modulators of membrane function (Palacios et al. 2005). In addition, these essential lipids are associated with human health, for example in the prevention of cardiovascular diseases (Huerlimann et al. 2010). It is of societal importance, therefore, to understand and improve EPA and DHA production for both shellfish nutrition (Marchetti et al., 2013) and human health. Other studies have, nevertheless, shown that light spectrum may influence secondary metabolism of lipids, such as sterol composition of Phaeodactylum tricornutum (Véron et al. 1996) or fatty acid composition in Chaetoceros calcitrans (Sánchez-Saavedra and Voltolina 1994). This study focused, therefore, on the effect of blue light and dilution rate on lipid class and fatty acid compositions of T. lutea. 


\section{Material and methods}

Microalgal culture

The techniques used have been previously described in Marchetti et al. (2013), so only a brief outline will be given here. Tisochrysis lutea (CCAP 927/14) was maintained under continuous culture in two 3.5-L photobioreactors (PBRs) made of two transparent polymethylmetacrylate (PMMA) columns (60 mm diameter) connected by two flanges. PBRs were sterilized with $5 \%$ peroxyacetic solution for 20 min before use and then filled with pre-acclimated cultures at $10^{6}$ cells $\mathrm{mL}^{-1}$ in Conway-enriched sea water $\left(3 \mathrm{~mL} \mathrm{~L}^{-1}\right.$, in order to prevent nutrient limitation), at $\approx 35 \mathrm{ppm}$ salinity. Each culture was previously pre-acclimated at its own experimental light spectrum, i.e. blue or white spectra, for 5-7 days. The white and blue light spectra used during this experiment have been already illustrated (see fig. 1 in Marchetti et al., 2012). Cultures were thermoregulated at $26 \pm 1^{\circ} \mathrm{C}$ by air conditioning and $\mathrm{pH}$ was maintained by automated $\mathrm{CO}_{2}$ injections at $\mathrm{pH} 7.2 \pm 0.1$ with a $\mathrm{pH}$ measurement loop (electrode Inpro 4800/225/PT1000, Mettler Toledo and HPT 63, LTH electronics Ltd). One culture was conducted for each dilution and light condition. Light was continuously delivered by six dimmable fluorescent tubes (blue or white), which incident irradiance was set at $300 \mu \mathrm{mol}$ photons $\mathrm{m}^{-2} \mathrm{~s}^{-1}$ using a dimming device. Two dilution rates ( $\mathrm{D}, 0.7$ or $0.2 \mathrm{~d}^{-1}$ ) were assayed using a dosing pump (KNF stepdos), for both light conditions, and checked daily by measuring the harvested volume. $\mathrm{D}=0.7 \mathrm{~d}^{-1}$ means that $70 \%$ of the culture was daily harvested and accordingly diluted with enriched seawater; whereas only $20 \%$ of the culture was daily harvested and diluted at $\mathrm{D}=0.2 \mathrm{~d}^{-1}$.

Analytical procedures

Cell quantification was done daily by two methods to establish steady-state growth, i.e., when values were stable for at least three consecutive days with less than $10 \%$ variation. Cell counting was performed by image analysis (IPS 32, Unilog) and microscope (Diaplan, 307-148001, Leitz; 3CCD color vision camera module, Donpisha) with Malassez slides and Lugol staining solution. Cell density was also determined by spectrophotometry at an absorbance of $800 \mathrm{~nm}$ ( $\mu$ Quant, Bio-tek instruments Inc.).

At steady state, three samples of $500 \times 10^{6}$ cells were filtered onto pre-combusted Whatman $\mathrm{GF} / \mathrm{C}$ filters $\left(450^{\circ} \mathrm{C}\right.$ for $\left.4 \mathrm{~h}\right)$ for each experimental condition. Samples were stored in pre-cleaned glass 
vials and sealed under nitrogen in $6 \mathrm{~mL}$ chloroform/methanol (2:1; v:v) (Folch et al. 1957) at $-20{ }^{\circ} \mathrm{C}$ for lipid extraction.

Samples were sonicated for $10 \mathrm{~min}$ and separated on a hydrated silica gel $(6 \%$, w/w) glass microcolumn (250 mm x $5 \mathrm{~mm}$ ) (Soudant et al. 1995). After checking separation efficiency on thin-layer chromatography (TLC) (Marty et al. 1992), the method was modified. Neutral lipids (NL) were eluted first using $10 \mathrm{~mL}$ chroroform, glycolipids (GL) using $20 \mathrm{~mL}$ of acetone, and phospholipids (PL) using 15 $\mathrm{mL}$ methanol. The different fractions collected were evaporated under nitrogen and stored under $2 \mathrm{~mL}$ of Folch reagent. Two sub-samples of $1 \mathrm{~mL}$ each were prepared, sealed under nitrogen, and stored at $-20^{\circ} \mathrm{C}$ for lipid-class and fatty-acid determination using TLC and gas chromatography (GC), respectively.

Samples for lipid class analysis were evaporated under nitrogen and re-suspended in $150 \mu \mathrm{L}$ of Folch mixture. Lipid classes were determined by TLC using $200 \times 100 \mathrm{~mm}$ silica-gel plates (Silicagel 60, Merck). Silica plates were subjected to a first elution to eliminate impurities with a solution of hexane:diethylether (1:1, v:v) for neutral lipids and a solution of methyl-acetate:isopropanol:chloroform: methanol: $\mathrm{KCl} 0.25 \%$ (10:10:10:4:3.6; v:v) for the other lipid classes (GL and PL). The chromatographic plates were activated for $20 \mathrm{~min}$ at $120^{\circ} \mathrm{C}$. The samples were placed on the plates with an automated instrument designed for TLC (Automatic TLC sampler 4 and software WinCATS, CAMAG). Standards employed for the identification of compounds within each lipid classes were sterols (St), alcohols, two different types of alkenones (ALK a and b), free fatty acids (FFA), triacylglycerol (TAG), glyceryl ethers (GE) and sterol esters (StE) for neutral lipids; sulfoquinovosylacylglycerol (SQDG), digalactosylacylglycerols (DGDG) and monogalactosylacylglycerols (MGDG) for glycolipids; and lysophosphatidyl-choline (LPC), sphingomyelin (Sm), phosphatidylcholine (PC), phosphatidylserine (PS), phosphatidylinositol (PI) phosphatidylethanolamine (PE) for phospholipids. All the lipid class standards and the chemicals used for HPTLC were purchased from Sigma-Aldrich, except for alkenones, which were lab-made standards. Neutral lipids were separated by two successive developments: first with a solution of hexane:diethylether: acetic acid (20:5:0.5; v:v) and, after drying, development in a hexane:diethylether (97:3; v:v) solution.

Glycolipids and phospholipids were separated under a simple development with a solution of methyl-acetate:isopropanol:chloroform: methanol: $\mathrm{KCl}$ 0.25\% (10:10:10:4:3.6; v:v). Plates were dipped in a $3 \% \mathrm{CuSO}_{4}$ and $8 \% \mathrm{H}_{3} \mathrm{PO}_{4}$ solution and heated at $160^{\circ} \mathrm{C}$ for $20 \mathrm{~min}$. The developed plates were analyzed with a Scanner-densitometer, equipped with a monochromatic, 370-nm light bulb, and lipid classes were 
identified and quantified comparing band intensity and position between standards and samples using winCATS software. Quantitative data were expressed in $\mathrm{g} \mathrm{g}^{-1}$ to avoid bias from cell size with dilution rate.

Samples of microalgal cultures for carbon (C) analysis were collected at steady-state, filtered (approximately $100 \times 10^{6}$ cells) through pre-combusted Whatman $\mathrm{GF} / \mathrm{C}$ glass filters and dried at $70^{\circ} \mathrm{C}$ for 48 h. Particulate carbon was determined by elemental analysis (EAGER 300, Thermo Scientific, CHN analyzer) and computed on the basis of the mean cell count at steady-state.

Fatty acids (FA) were analyzed using GC after the addition of the free fatty acid 23:0 (2.3 $\mu \mathrm{g})$ as an internal standard for quantitative determinations. Samples were evaporated under nitrogen and transesterified with $1 \mathrm{~mL}$ of $\mathrm{BF}_{3}-\mathrm{MeOH}\left(14 \%\right.$ by weight) for $10 \mathrm{~min}$ at $95^{\circ} \mathrm{C}$ (Metcalfe and Schmitz 1961). After cooling, $1 \mathrm{~mL}$ of hexane and $1 \mathrm{~mL}$ of water were added to samples, which were agitated gently and centrifuged (1000 X g, $10 \mathrm{~min})$. The organic upper phase, which contains the fatty acid methyl esters (FAMEs), was collected and cleaned with $1 \mathrm{~mL}$ of water that was subsequently eliminated. FAMEs were separated and quantified by GC using an "Autosystem GC" (Perkin-Elmer) equipped with a cyanopropyl-cyloxane capillary column (BPX 70, $60 \mathrm{~m}$ length x $0.25 \mathrm{~mm}$ i.d. x $0.25 \mu \mathrm{m}$ film thickness), with a split-splitless injector and a FID detector. FAs were identified using the software Galaxie and expressed per unit of $\mathrm{C}$.

\section{Statistical analysis}

Group normality was initially evaluated using the Shapiro-Wilk test, and homogeneity of variances was checked prior to analyses by the Barlett test. Percentage data were transformed (arcsin square root of xi $100^{-1}$ ) to normalize variance (Sokal and Rohlf 1995). Two-way analysis of variance was performed for all biochemical variables (i.e., proportion and quantification of lipid class and fatty acid compositions within each lipid fraction) using Statgraphics Centurion XV software to test the effect of dilution rate and spectrum of light. When a significant effect $(P<0.05)$ was found, Fisher's least significant difference (LSD) test was used to determine significant differences between experimental conditions.

FA data were analyzed statistically, with a similarity percentage analysis (SIMPER) being performed on the relative FA percentage data to demonstrate the differences in NL, GL and PL FA 
composition between dilution rate of the culture $\left(0.2 \mathrm{~d}^{-1}, 0.7 \mathrm{~d}^{-1}\right)$, and spectrum of light (white or blue) in T. lutea. SIMPER identifies the FAs that contribute most to the variance between tested conditions. Only the FAs that cumulatively contributed up to $80 \%$ of the dissimilarities recorded were selected to identify the differences in FA profile between culture conditions (Clarke and Gorley 2006). Data on the relative FA percentage of the samples were logarithmically $(\log [\mathrm{x}+1])$ transformed and converted into a BrayCurtis similarity matrix to start the multivariate analyses. The Bray-Curtis similarity matrix was used for a one-way analysis of similarities (ANOSIM) to test whether samples within NL, GL or PL fractions clustered by dilution rate or light spectrum. ANOSIM calculates a global R statistic that weights the differences between groups, with $\mathrm{R}=1, \mathrm{R}=0.5$ and $\mathrm{R}=0$ indicating a perfect, satisfactory, or poor separation of the clusters, respectively (Clarke and Gorley 2006). SIMPER and ANOSIM analysis of the relative FA percentages were performed using PRIMER (Quest Research Limited, Albany, Auckland, New Zealand, version 5).

\section{Results}

Lipid class identification and proportions

In the neutral lipids (NL), 10 different groups of compounds were found in NL (Fig. 1). There were two spots of pigments, sterols (St), free fatty acids (FFA), unidentified NL 1 and 2 (NLx ${ }_{1}$ and $\mathrm{NLx}_{2}$ ), triacylglycerol (TAG), alkenones a and b (ALK a and ALK b), and hydrocarbons (HC). TAG, St and hydrocarbons (HC) were the main compounds, accounting for $66-79 \%$ of total NL. Relative contents of $\mathrm{HC}$ and unidentified $\mathrm{NL} 1$ and $2\left(\mathrm{NLx}_{1}\right.$ and $\left.\mathrm{NLx}_{2}\right)$ were affected significantly by dilution rate $(D)$ (Table 1). Specifically, the proportion of $\mathrm{NLx}_{1}$ and $\mathrm{NLx}_{2}$ increased at a high dilution rate $\left(D=0.7 \mathrm{~d}^{-1}\right)$; whereas, the HC proportion decreased significantly. Relative contents of TAG and FFA were affected significantly by $D$, and the interacting effects of light spectrum with $D$. The proportion of TAG was enhanced at low dilution rate $\left(D=0.2 \mathrm{~d}^{-1}\right)$ under blue light; whereas, FFA increased at high dilution rate under blue light. The proportion of sterol $(\mathrm{St})$ varied with light spectrum and $D$, exhibiting the highest relative content at high dilution rate and under blue light (19\%). Alkenone a (ALK a) relative content was modified by light spectrum, with highest values under white light.

In the glycolipids (GL), 5 different groups of compounds were found (Fig. 1), with MGDG, SQDG and the unidentified GL 2 as main compounds accounting for 87-92\% of total GL. The relative 
content of SQDG was dependent upon $D$, with higher values at high $D\left(0.7 \mathrm{~d}^{-1}\right)$ (Table 2). Relative content of DGDG was affected significantly by $D$, light spectrum, and the interaction. The highest proportion of DGDG was recorded at low $D\left(0.2 \mathrm{~d}^{-1}\right)$ and blue light; whereas, the lowest relative content of DGDG occurred at high $D\left(0.7 \mathrm{~d}^{-1}\right)$ regardless of light spectrum.

Differentiation between groups in the PL was not possible because of superposition of bands and incorrect alignment with standards (Fig. 2).

\section{Lipid class quantification}

Within each lipid class (NL, GL and PL), only some compounds were quantified with the calibration curve used in this study (TAG, St and HC for NL and MGDG and DGDG for GL; Table 3). TAG and St contents were significantly related to $D$, showing highest values at low $D\left(70\right.$ and $12 \times 10^{3} \mathrm{~g}$ $\mathrm{g} \mathrm{C}^{-1}$, respectively: Table 3 ). HC content varied significantly with both $D$ and light spectrum, with the highest value recorded at low $D$ under white light (Table 3). DGDG content was significantly affected by $D$ and the interaction of both factors (Table 3), with the highest value detected at low $D$ under white light (Table 3).

Fatty acid quantification

The main FA in NL were 14:0, 18:1(n-9), 16:0 and 18:4(n-3), accounting from 69 to $82 \%$ of TFA in NL under all experimental conditions (Table 4). Total fatty acid (TFA), saturated fatty acid (SFA), and monounsaturated fatty acid (MUFA) contents in NL were affected significantly by $D$ (Table 5). These components were stored in NL at low $D$ with approximately double at high $D$ (Table 4). The main FA in SFA were 14:0 and 16:0, which showed increased contents at low $D\left(30\right.$ and $16 \times 10^{3} \mathrm{~g} \mathrm{~g} \mathrm{C}^{-1}$ at $0.2 \mathrm{~d}^{-1}$ vs. $14-16$ and 7-8 at $0.7 \mathrm{~d}^{-1}$ : Table 4). MUFA content was mainly driven by $18: 1(\mathrm{n}-9)$, which increased at low $D\left(25 \times 10^{3} \mathrm{~g} \mathrm{~g} \mathrm{C}^{-1}\right.$ at $0.2 \mathrm{~d}^{-1} v s 9-11 \times 10^{3} \mathrm{~g} \mathrm{~g} \mathrm{C}^{-1}$ at $0.7 \mathrm{~d}^{-1}:$ Table 4). The polyunsaturated fatty acids (PUFA) 20:4(n-6) and 20:5(n-3) also were modulated by $D$ (Table 5), showing the lowest values for both FA at high $D$ (Table 4). In contrast, 22:6n-3 content was similar regardless to experimental conditions (3-4 x $10^{3} \mathrm{~g} \mathrm{~g} \mathrm{C}^{-1}$; Table 4); whereas, relative DHA values reached 4.5 and $6.5 \%$ of TFA in NL at low and high $D$, respectively. 
The main changes in FA profile (expressed in weight percentage) in NL attributable to light spectrum were associated with 18:0, 16:1(n-7), 18:1(n-9), 16:2(n-6), 18:3(n-3), 18:4(n-3), 18:5(n-3), 20:4(n-6), 22:5(n-6), 22:5(n-3) and 22:6(n-3) (8.7\% dissimilarity, SIMPER), and the overall difference was not statistically significant (Global R: -0.059 , Stress $=0.641$, ANOSIM).

The main changes of FA profile (expressed in weight percentage) in NL attributable to dilution rate were associated with 18:0, 16:1(n-7), 18:1(n-9), 16:2(n-6), 18:3(n-3), 18:4(n-3), 18:5(n-3), 22:5(n-6), 22:5(n-3) and 22:6(n-3) (Fig. 3A) (11.3\% dissimilarity, SIMPER), and the overall difference was statistically significant (Global R: 0.844, Stress $=0.002$, ANOSIM).

The main FA in GL were 14:0, 18:4(n-3), 18:1(n-9) and 16:0, accounting for $72-80 \%$ of TFA in GL in all experimental conditions (Table 4). The effect of $D$ and light spectrum on FA contents in GL was low (Table 5). MUFA content in GL was significantly lower at high $D\left(13-14 \mathrm{~g} \mathrm{~g} \mathrm{C}^{-1}\right)$ compared to low $D\left(19-22 \times 10^{3} \mathrm{~g} \mathrm{~g} \mathrm{C}^{-1}\right)$ (Tables 4 and 5). The MUFA 18:1(n-9) exhibited a similar pattern as total MUFA, increasing significantly at low $D$ (Table 4). Great amounts of 18:4(n-3) were found in GL compared to the other FA classes (NL and PL; Table 4). Higher, but not significantly different, quantities were observed when $T$. lutea was grown under low $D\left(26-28 \times 10^{3} \mathrm{~g} \mathrm{~g} \mathrm{C}^{-1}\right)$ compared to high $D(20-22 \times$ $10^{3} \mathrm{~g} \mathrm{~g} \mathrm{C}^{-1}$, Table 4). The amount of $18: 5(\mathrm{n}-3)$ was significantly lower at low $D\left(0.4-0.7 \times 10^{3} \mathrm{~g} \mathrm{~g} \mathrm{C}^{-1}\right)$ than at high $D\left(D=0.7 \mathrm{~d}^{-1}: 2-3 \times 10^{3} \mathrm{~g} \mathrm{~g} \mathrm{C}^{-1}\right.$; Table 4). The PUFA 20:4(n-6) was undetected in GL. The content of 20:5(n-3) was modulated by $D$; whereas, a significant interaction between $D$ and light spectrum was found (Table 5). The highest quantities of 20:5(n-3) were recorded at high $D$ under white light; whereas, the lowest values were found at low $D$ under white light (Table 4). Similar contents of 22:6(n-3) were detected at all experimental conditions (2.4-2.9 x 10 $\mathrm{g} \mathrm{g} \mathrm{C}^{-1}$; Table 4). TFA in GL varied from 85 to $101 \times 10^{3} \mathrm{~g} \mathrm{~g} \mathrm{C}^{-1}$ (Table 4), showing no differences between culture conditions.

The main changes in FA profile (expressed in weight percentage) in GL attributable to light spectrum were associated with 18:0, 16:1(n-9), 16:1(n-7), 18:1(n-9), 16:2(n-6), 16:2(n-4), 18:3(n-3), 18:4(n-3), 18:5(n-3), 20:5(n-3), and 22:6(n-3) (7.0\% dissimilarity, SIMPER), and the overall difference was not statistically significant (Global R: -0.02 , Stress $=0.522$, ANOSIM).

The main changes in FA profile (expressed in weight percentage) in GL attributable to dilution rate were associated with 18:0, 16:1(n-9), 16:1(n-7), 18:1(n-9), 16:2(n-6), 18:2(n-6), 18:3(n-3), 18:4(n-3), 18:5(n-3), 20:5(n-3), and 22:6(n-3) (Fig. 3B) (8.9\% dissimilarity, SIMPER), and the overall difference was statistically significant (Global R: 0.954, Stress $=0.002$, ANOSIM). 
The main FA in PL were 14:0, 22:6(n-3), 16:0 and 18:1(n-9), accounting for 73-79\% of TFA in PL in all experimental conditions (Table 4). TFA in PL were enhanced at low $D$ (Tables 4 and 5). MUFA in PL showed significantly higher amounts at low $D\left(14-17 \times 10^{3} \mathrm{~g} \mathrm{~g} \mathrm{C}^{-1}\right)$ than at high $D\left(8-10 \times 10^{3} \mathrm{~g} \mathrm{~g}\right.$ $\mathrm{C}^{-1}$; Table 4 and 5). Total PUFA and n-3 PUFA were modulated by $D$ and light spectrum (Table 5). The highest total PUFA content was observed at low $D$ under blue light $\left(30 \times 10^{3} \mathrm{~g} \mathrm{~g} \mathrm{C}^{-1}\right)$; whereas, the lowest value was recorded at high $D$ under white light $\left(19 \times 10^{3} \mathrm{~g} \mathrm{~g} \mathrm{C}^{-1}\right.$; Table 4). The highest amounts of n-3 PUFA were found at low $D$ under blue light $\left(28 \times 10^{3} \mathrm{~g} \mathrm{~g} \mathrm{C}^{-1}\right)$; whereas, no significant differences were observed for the other experimental conditions (18-20 x $10^{3} \mathrm{~g} \mathrm{~g} \mathrm{C}^{-1}$; Table 4). The contents of $\mathrm{n}-6$ PUFA and 20:4(n-6) were significantly affected by $D$ and light spectrum and the interaction (Table 5). The highest content of n-6 PUFA was observed at low $D$ under white light (4 x $10^{3} \mathrm{~g} \mathrm{~g} \mathrm{C}^{-1}$; Table 4); whereas, no significant differences were observed for the other experimental conditions $\left(2 \times 10^{3} \mathrm{~g} \mathrm{~g} \mathrm{C}^{-1}\right.$; Table 4). The amount of 20:5(n-3) was significantly enhanced at high $D$ (Tables 4 and 5). The content of 22:6(n-3) was significantly affected by $D$ and light spectrum (Table 5), showing the highest amount at low $D$ under blue light $\left(17 \times 10^{3} \mathrm{~g} \mathrm{~g} \mathrm{C}^{-1}\right)$ and the lowest value at high $D$ under white light $\left(11 \times 10^{3} \mathrm{~g} \mathrm{~g} \mathrm{C}^{-1}\right.$; Table 4).

The main changes in FA profile (expressed in weight percentage) in PL attributable to light spectrum were associated with 14:0, 18:0, 16:1(n-7), 18:1(n-7), 16:2(n-4), 18:2(n-6), 18:3(n-3), 18:4(n-3), 22:5(n-6), 22:5(n-3), and 22:6(n-3) (6.8\% dissimilarity, SIMPER), and the overall difference was not statistically significant (Global R: -0.04 , Stress $=0.514$, ANOSIM).

The main changes in FA profile (expressed in weight percentage) in PL attributable to dilution rate were associated with 14:0, 18:0, 16:1(n-7), 16:2(n-4), 18:2(n-6), 18:3(n-3), 18:4(n-3), 20:5(n-3), 22:6(n6), and 22:6(n-3) (Fig. 3C) (8.1\% dissimilarity, SIMPER), and the overall difference was statistically significant (Global R: 0.644, Stress =0.008, ANOSIM).

\section{Discussion}

In the present study, lipid class composition and fatty acid profile of Tisochrysis lutea were shown to respond selectively and significantly to different qualities of light (blue or white) and two dilution rates (low $D: 0.2 \mathrm{~d}^{-1}$ and high $D: 0.7 \mathrm{~d}^{-1}$ ). Findings have implications for aquaculture and industrial uses of this widely-cultured flagellate. 
Lipid and fatty acid composition variations with dilution rate and light spectrum

Quantities of NL and GL classes were not modified significantly in T. lutea cultured under blue light compared to white. In NL, the proportion of TAG at high $D$ and the proportion of ALK a, at both dilution rates, decreased with blue light. To our knowledge, there is no study that deeply investigated variation of lipid classes under different light spectra, thus making very difficult comparison of our data with literature. Nonetheless, St variation under different light spectra (red, blue, white, green and yellow) was studied in Phaeodactylum tricornutum (Véron et al. 1996). These authors demonstrated that at a similar temperature $\left(23\right.$ vs. $\left.26^{\circ} \mathrm{C}\right)$, total quantity of St was not affected by blue vs. white light, thus confirming St stability found in the present work (7-12 x $\left.10^{3} \mathrm{~g} \mathrm{~g} \mathrm{C}^{-1}\right)$ under both light spectra. St are essential constituents of cell membranes (Volkman et al. 1981). In the present study, St content was significantly reduced at high $D$, which may increase membrane fluidity.

TAG, the main energy source material for cellular division (Dunstan et al. 2005), increased under low $D\left(70-71 \times 10^{3} \mathrm{~g} \mathrm{~g} \mathrm{C}^{-1}\right)$; content was 2 to 3 -fold higher than at high $D\left(22-33 \times 10^{3} \mathrm{~g} \mathrm{~g} \mathrm{C}^{-1}\right)$. These observations are in agreement with previous results in T. lutea which showed that NL increased at low $D$ as a result of light limitation (Saoudi-Helis et al. 1994).

Alkenones could be quite abundant in most Prymnesiophyceae and particularly in T. lutea (Volkman et al. 1980, 1981; Marlowe et al. 1984; Dunstan et al. 2005). Alkenone biosynthesis and cellular machinery involved in production remain unknown (Eltgroth et al. 2005). Versteegh et al. (2001) speculated that alkenones may also interact in the photosynthetic pathway. Other authors suggested that alkenones may have a storage function (Eltgroth et al. 2005; Shi et al. 2015). Alkenones may be synthetized in the chloroplast and then exported to cytoplasm in the form of lipid bodies for storage and eventual metabolism (Eltgroth et al. 2005). We found that the sum of the relative content of the bands ALK $\mathrm{a}$ and $\mathrm{b}$ were affected by light spectrum (Table 1), showing a lower proportion under blue light. In our previous work (Marchetti et al. 2013), which evaluated the effect of blue light on the biochemical composition and photosynthetic activity of T. lutea, we found lower chlorophyll $a$ content per cell under blue light. Photosynthetic activity, however, was enhanced under blue light, resulting in higher protein synthesis under this spectrum of light at the expense of carbon storage compounds, such as alkenones.

Glycolipids are constituents of photosynthetic membranes in the chloroplast (Parrish 1987; Klyachko-Gurvich et al. 1999). MGDG and DGDG are uncharged galactolipids that are the main 
constituents of thylakoid membranes (Kobayashi 2016). These compounds provide a lipid bilayer matrix for photosynthetic complexes (Kobayashi 2016). SQDG is an anionic glycolipid with a negative charge on the head group (Kobayashi 2016). SQDG is important for chloroplast function and structure (Yu and Benning 2003). The relative content of SQDG varied according to $D$; whereas, DGDG proportion was affected by $D$ and the spectrum of light and the interaction between both factors. DGDG increased under low $D$ at the expense of SDQG. In our work, MGDG proportion remained unchanged despite an important role in the regulation of the structure and function of photosynthetic membrane proteins as suggested by previous studies (Bruce 1998; Zhou et al. 2009). DGDG and MGDG are rich in PUFAs; whereas, SQDG are rich in 14:0, 16:0 and 16:1n-7, which accounts for 70\% of total fatty acids in this class in I. galbana (Alonso et al. 1998). Hence, under high D, i.e. under high irradiance, photosynthetic membranes decrease the level of unsaturation to adjust fluidity of photosynthetic membranes by the increase in the proportion of GL with a higher level of SFAs than PUFAs.

SFA (14:0 and 16:0) and MUFA (18:1(n-9)) were predominant in lipid storage (NL) of T. lutea. SFA and MUFA quantities in NL were significantly higher at low $D$, concomitant with the accumulation of TAG content at low $D$. The significant increases in proportions of SFA and MUFA in NL with the decreasing dilution rate in our study (64-76\% vs. $80-82 \%$ of TFA for the sum of SFA+MUFA in NL in 0.7 and $0.2 \mathrm{~d}^{-1}$, respectively) are in agreement with Saoudi-Helis et al. (1994), in which SFA and MUFA proportions in $T$. lutea increased as $D$ decreased from 1 to $0.33 \mathrm{~d}^{-1}$. We found no significant differences in the content of SFA and MUFA in NL under the different light spectra, as also reported in I. galbana by Yoshioka et al. (2012).

GL and PL are, respectively, rich in short chain PUFAs (C18) and long chain PUFAs (C22). The significant increase in 18:5(n-3) proportion in GL at high $D$ (from 0.6 to $2.8 \%$ of TFA in GL in 0.2 and $0.7 \mathrm{~d}^{-1}$, respectively) could be directly linked to thylakoid membrane changes (Mortensen et al. 1988; Sukenik and Wahnon 1991; Saoudi-Helis et al. 1994). Hence, the variation may allow cells to respond to increased growth rate and photosynthetic activity under high cellular renewal (i.e. high $D$ ) (KlyachkoGurvich et al. 1999). More precisely, the enhancement of unsaturation level under high renewal rate inevitably increases membrane fluidity (Klyachko-Gurvich et al. 1999; Tzovenis et al. 2003).

Overall, PUFA content and particularly n-3 PUFAs (18:3(n-3), 18:4(n-3) and 22:6(n-3)) in PL were significantly higher under blue light at low $D$, thus indicating an increase in lipid unsaturation under blue light at low D. Sánchez-Saavedra and Voltolina (1994) also reported enhancement in C18 fatty acids 
in Chaetoceros sp. grown under blue light compared to white light. Yoshioka et al. (2012) found a higher proportion of 22:6(n-3) in PL of I. galbana grown under blue intermittent light compared to white intermittent light. These authors suggested that blue intermittent light for I. galbana cultivation promoted 22:6(n-3) incorporation into the PL fraction.

In summary, the more profound effects on lipid class and fatty acid compositions were attributable to dilution rate that highly influenced growth rate and light availability.

\section{Application to hatcheries}

Lipid quantity and quality have strong effects on bivalve larval and post-larval performance in terms of survival and growth (Powell et al. 2002; Delaunay et al. 1993; Nevejan et al. 2003a). Triacylglycerols has been identified as a great source of energy for bivalve larvae, especially in periods of low food availability or in starvation (Gallager et al. 1986; Whyte et al. 1992; Ben Kheder et al. 2010 a, b). Triaglycerol content is also a predictor of growth rate in Crassostrea gigas larvae (Waldock and Nascimento 1979), Pecten maximus (Delaunay et al. 1992), Argopecten purpuratus (Nevejan et al. 2003b) and Placopecten magellanicus (Pernet et al. 2006). Our data showed that, at low dilution rate, TAG content sharply increased. Accordingly, it would be beneficial to culture T. lutea at low dilution rate to promote TAG production and storage in microalgae to be used as feeds for bivalve larvae.

Essential fatty acids (EFAs), particularly omega-3 fatty acids 20:5(n-3) (EPA) and 22:6(n-3) (DHA), are important to bivalve growth and development (Langdon and Waldock 1981) because they are major membrane components (Hendriks et al. 2003) and possible modulators of membrane function (Palacios et al. 2005). Several studies have attributed a higher importance to $22: 6(n-3)$ in relation to 20:5(n-3) in broodstock and larvae (Marty et al. 1992; Delaunay et al. 1993; Whyte et al. 1992; Soudant et al. 1996), because of the major role that 22:6(n-3) plays in maintaining the structural and functional integrity of cell membranes. In contrast, 20:5(n-3) serves mainly an energy source. In our study, a significant increase in 22:6(n-3) at low $D$ under blue light was observed in $T$. lutea. As a consequence, the application of T. lutea rich in 22:6(n-3) may lead to a higher larval performance and settlement success.

The present study highlights the effects of blue light and dilution rate on fatty acids and lipid class composition of $T$. lutea cultured in photobioreactor and harvested at steady state. Future research should confirm the importance of these changes on bivalve culture. 


\section{Acknowledgements}

The development of this work was made possible by technical and financial support (Cifre fellowship) of the French commercial oyster hatchery Vendée Naissain (www.francenaissain.com) for J. Marchetti. Great thanks to G. Wikfors from Milford laboratory for reviewing the first version of this manuscript and improving the English.

\section{References}

Alonso DL, Belarbi E-H, Fernández-Sevilla JM, Rodríguez-Ruiz J, Grima EM (2000) Acyl lipid composition variation related to culture age and nitrogen concentration in continuous culture of the microalga Phaeodactylum tricornutum. Phytochem 54:461-471

Aranda-Burgos JA, da Costa F, Nóvoa S, Ojea J, Martínez-Patiño D (2014) Effects of microalgal diet on growth, survival, biochemical and fatty acid composition of Ruditapes decussatus larvae. Aquaculture 420-421:38-48

Bendif EM, Probert I, Schroeder DC, de Vargas C (2013) On the description of Tisochrysis lutea gen. nov. sp. nov. and Isochrysis nuda sp. nov. in the Isochrysidales, and the transfer of Dicrateria to the Prymnesiales (Haptophyta). J Appl Phycol 25 (6):1763-1776

Ben Kheder R., Quéré C., Moal J., Robert R., 2010 a. Effect of nutrition on Crassostrea gigas larval development and the evolution of physiological indices. Part A: quantitative and qualitative diet effects. Aquaculture, 305, 165-173.

Ben Kheder R., Quéré C., Moal J., Robert R., 2010 b. Effect of nutrition on C. gigas larval development and evolution of physiological indices. Part B: Temporary starvation effects. Aquaculture, 308, 174-182.

Brown MR, Dunstan GA, Jeffrey SW, Volkman JK, Barrett SM, Le Roi JM (1993) The influence of irradiance on the biochemical composition of the prymnesiophyte Isochrysis sp. (Clone T-iso). J Phycol 29:601-612.

Bruce BD (1998) The role of lipids in plastid protein transport. Plant Mol Biol 38:223-246. doi:10.1023/a:1006094308805 
Clarke KR, Gorley RN (2006) PRIMER v6: user manual/tutorial (Plymouth routines in multivariate ecological research). Plymouth: Primer-E Ltd

Delaunay F, Marty Y, Moal J, Samain JF (1992) Growth and lipid class composition of Pecten maximus (L.) larvae grown under hatchery conditions. J Exp Mar Biol Ecol 163:209-219

Delaunay F, Marty Y, Moal J, Samain JF (1993) The effect of monospecific algal diets on growth and fatty acid composition of Pecten maximus (L.) larvae. J Exp Mar Biol Ecol 173:163-179

Dunstan GA, Brown MR, Volkman JK (2005) Cryptophyceae and rhodophyceae; chemotaxonomy, phylogeny, and application. Phytochem 66:2557-2570

Dunstan GA, Volkman JK, Barrett SM, Garland CD (1993) Changes in the lipid composition and maximisation of the polyunsaturated fatty acid content of three microalgae grown in mass culture. J Appl Phycol 5:71-83.

Eltgroth ML, Watwood RL, Wolfe GV (2005) Production and cellular localization of neutral long-chain lipids in the haptophyte algae Isochrysis galbana and Emiliania huxley. J Phycol 41 (5):10001009

Ewart JW, Pruder GD (1981) Comparative growth of Isochrysis galbana Parke and Isochrysis aff. galbana, clone T-iso at four temperatures and three light intensities. J World Maricult Soc 12:333-339. doi:10.1111/j.1749-7345.1981.tb00265.x

Fernández-Reiriz MJ, Pérez-Camacho A, Ferreiro MJ, Blanco J, Planas M, Campos MJL, U. (1989) Biomass production and variation in the biochemical profile (Total protein, carbohydrates, RNA, lipids and fatty acids) of seven species of marine microalgae. Aquaculture 83:17-37

Folch J, Lees M, Stanley GHS (1957) A simple methods for the isolation and purification of total lipids from animal tissues. J Biol Chem 226:497-509

Gallager SM, Mann R, Sasaki GC (1986) Lipid as an index of growth and viability in three species of bivalve larvae. Aquaculture 56:81-103

Gostan J, Lechugadeveze C, Lazzara L (1986) Does blue light affect the growth of Chaetoceros protuberans (Bacillariophyceae). J Phycol 22:63-71

Hendriks IE, van Duren LA, Herman PMJ (2003) Effect of dietary polyunsaturated fatty acids on reproductive output and larval growth of bivalves. J Exp Mar Biol Ecol 296:199-213. doi:10.1016/s0022-0981(03)00323-X 
Huerlimann R, de Nys R, Heimann K (2010) Growth, lipid content, productivity, and fatty acid composition of tropical microalgae for scale-up production. Biotechnol Bioeng 107:245-257. doi:10.1002/bit.22809

Klyachko-Gurvich GL, Tsoglin LN, Doucha J, Kopetskii J, Shebalina IB, Semenenko VE (1999) Desaturation of fatty acids as an adaptive response to shifts in light intensity. Physiol Plantarum 107:240-249. doi:10.1034/j.1399-3054.1999.100212.x

Knauer J, Barrett SM, Volkman JK, Southgate PC (1999) Assimilation of dietary phytosterols by Pacific oyster Crassostrea gigas spat. Aquac Nutr 5:257-266

Kobayashi K (2016) Role of membrane glycerolipids in photosynthesis, thylakoid biogenesis and chloroplast development. J Plant Res 129 (4):565-580

Langdon CJ, Waldock MJ (1981) The effect of algal and artificial diets on the growth and fatty acid composition of Crassostrea gigas spat. J Mar Biol Assoc UK 61:431-448

Marchetti J, Bougaran G, Jauffrais T, Lefebvre S, Rouxel C, Saint-Jean B, Lukomska E, Robert R, Cadoret JP (2013) Effects of blue light on the biochemical composition and photosynthetic activity of Isochrysis sp. (T-iso). J Appl Phycol 25: 109-119. doi:10.1007/s10811-012-9844-y

Marchetti J, Bougaran G, Le Dean L, Mégrier C, Lukomska E, Kaas R, Olivo E, Baron R, Robert R, Cadoret JP (2012) Optimizing conditions for the continuous culture of Isochrysis affinis galbana relevant to commercial hatcheries. Aquaculture 326-329:106-115

Marlowe IT, Green JC, Neal AC, Brassell SC, Eglinton G, Course PA (1984) Long chain (n-C37 - C39) alkenones in the Prymnesiophyceae. Distribution of alkenones and other lipids and their taxonomic significance. Brit Phycol J 19:203-216. doi:10.1080/00071618400650221

Marshall R, McKinley S, Pearce CM (2010) Effects of nutrition on larval growth and survival in bivalves. Rev Aquacult 2:33-55. doi:10.1111/j.1753-5131.2010.01022.x

Marty Y, Delaunay F, Moal J, Samain JF (1992) Changes in the fatty acid composition of Pecten maximus (L.) during larval development. J Exp Mar Biol Ecol 163:221-234

Metcalfe LD, Schmitz AA (1961) The rapid preparation of fatty acid esters for gas chromatography analysis. Anal Chem 33:363-364

Mortensen SH, Borsheim KY, Rainuzzo JR, Knutsen G (1988) Fatty acid and elemental composition of the marine diatom Chaetoceros neogracilis Schütt. Effect of silicate deprivation, temperature and light intensity. J Exp Mar Biol Ecol 122:173-185 
Napolitano GE, Ackman RG, Ratnayake WMN (1990) Fatty acid composition of three cultured algal species (Isochrysis galbana, Chaetoceros gracilis and Chaetoceros calcitrans) used as food for bivalve larvae. J World Aquacult Soc 21:122-130. doi:10.1111/j.1749-7345.1990.tb00532.x

Nevejan N, Courtens V, Hauva MG, G. (2003a) Effect of lipid emulsions on production and fatty acid composition of eggs of the scallop Argopecten purpuratus. Mar Biol 143:327-338

Nevejan N, Saez I, Gajardo G, Sorgeloos P (2003b) Supplementation of EPA and DHA emulsions to a Dunaliella tertiolecta diet: effect on growth and lipid composition of scallop larvae, Argopecten purpuratus (Lamarck, 1819). Aquaculture 217:613-632

Palacios E, Racotta IS, Kraffe E, Marty Y, Moal J, Samain JF (2005) Lipid composition of the giant lion's-paw scallop (Nodipecten subnodosus) in relation to gametogenesis: I. Fatty acids. Aquaculture 250:270-282

Parrish CC (1987) Separation of aquatic lipid classes by Chromarod Thin-Layer Chromatography with measurement by Iatroscan Flame Ionization Detection. Can J Fish Aquat Sci 44:722-731

Pernet F, Bricelj VM, Cartier S (2006) Lipid class dynamics during larval ontogeny of the sea scallops, Placopecten magellanicus, in relation to metamorphic success and response to antibiotics. J Exp Mar Biol Ecol 329:265-280

Ponis E, Parisi G, Le Coz J-R, Robert R, Zittelli GC, Tredici MR (2006) Effect of the culture system and culture technique on biochemical characteristics of Pavlova lutheri and its nutritional value for Crassostrea gigas larvae. Aquac Nutr 12:322-329

Powell EN, Bochenek EA, Klinck JM, Hofmann EE (2002) Influence of food quality and quantity on the growth and development of Crassostrea gigas larvae: a modelling approach. Aquaculture 2010:89-117

Reitan KI, Rainuzzo JR, Olsen Y (1994) Influence of lipid composition of live feed on growth, survival and pigmentation of turbot larvae. Aquacult Int 2:33-48. doi:10.1007/bf00118531

Rivkin RB (1989) Influence of irradiance and spectral quality on the carbon metabolism of phytoplankton: 1. Photosynthesis, chemical composition and growth. Mar Ecol Prog Ser 55:291304

Sánchez-Saavedra MdP, Voltolina D (1994) The chemical composition of Chaetoceros sp. (Bacillariophyceae) under different light conditions. Comp Biochem Phys B 107:39-44 
Saoudi-Helis L, Dubacq J, Marty Y, Samain J, Gudin C (1994) Influence of growth rate on pigment and lipid composition of the microalga Isochrysis aff. galbana clone T.iso. J Appl Phycol 6:315-322. doi:10.1007/bf02181945

Schenk PM, Thomas-Hall SR, Stephens E, Marx UC, Mussgnug JH, Posten C, Kruse O, Hankamer B (2008) Second generation biofuels: High-efficiency microalgae for biodiesel production. BioEnergy Res 1:20-43

Shi Q, Araie H, Bakku RK, Fukao Y, Rakwal R, Suzuki I, Shiraiwa Y (2015) Proteomic analysis of lipid body from the alkenone-producing marine haptophyte alga Tisochrysis lutea. Proteomics 15 (2324):4145-4158

Sokal RR, Rohlf FJ (1995) Biometry. The principles and practice of statistics in biological research. Third edition edition, New York, Freeman.

Soudant P, Marty Y, Moal J, Robert R, Quéré C, Le Coz JR, Robert R, Samain JF (1996) Effect of food fatty acid and sterol quality on Pecten maximus female gonad composition and reproduction process. Aquaculture 143:361-378

Soudant P, Marty Y, Moal J, Samain JF (1995) Separation of major polar lipids in Pecten maximus by high-performance liquid chromatography and subsequent determination of their fatty acids using gas chromatography. J Chromatogr B-Biomed Appl 673:15-26

Spolaore P, Joannis-Cassan C, Duran E, Isambert A (2006) Review: commercial applications of microalgae. J Biosci Bioeng 101:87-96

Sukenik A, Wahnon R (1991) Biochemical quality of marine unicellular algae with special emphasis on lipid composition. I. Isochrysis galbana. Aquaculture 97 (1):61-72

Tzovenis I, De Pauw N, Sorgeloos P (2003) Optimisation of T-ISO biomass production rich in essential fatty acids II. Effect of different light regimes on the production of fatty acids. Aquaculture 216 $(1-4): 223-242$

Véron B, Billard C, Dauguet J-C, Hartmann M-A (1996) Sterol composition of Phaeodactylum tricornutum as influenced by growth temperature and light spectral quality. Lipids 31:989-994. doi:10.1007/bf02522694

Versteegh GJM, Riegman R, de Leeuw JW, Jansen JHF (2001) $U^{\mathrm{K} 37}$ values for Isochrysis galbana as a function of culture temperature, light intensity and nutrient concentrations. Org Geochem 32 (6):785-794 
Volkman JK, Eglinton G, Corner EDS, Sargent JR (1980) Novel unsaturated straight-chain C37-C39 methyl and ethyl ketones in marine sediments and a coccolithophore Emiliania huxleyi. Phys Chem Earth 12:219-227

Volkman JK, Smith DJ, Eglinton G, Forsberg TEV, Corner EDS (1981) Sterol and fatty acid composition of four marine haptophycean algae. J Mar Biol Assoc UK 61:509-527. doi:doi:10.1017/S0025315400047111

Waldock MJ, Nascimento IA (1979) Triacylglycerol composition of Crassostrea gigas larvae fed on different algal diets. Mar Biol Lett 1:77-86

Whyte JNC, Bourne N, Ginther NG, Hodgson CA (1992) Compositional changes in the larva to juvenile development of the scallop Crassadoma gigantea (Gray). J Exp Mar Biol Ecol 163:13-29

Wynne D, Rhee GY (1986) Effects of light intensity and quality on the relative $\mathrm{N}$ and P requirement (the optimum N:P ratio) of marine planktonic algae. J Plankton Res 8:91-103. doi:10.1093/plankt/8.1.91

Yoshioka M, Yago T, Yoshie-Stark Y, Arakawa H, Morinaga T (2012) Effect of high frequency of intermittent light on the growth and fatty acid profile of Isochrysis galbana. Aquaculture 338:111-117

Yu B, Benning C (2003) Anionic lipids are required for chloroplast structure and function in Arabidopsis. Plant J 36 (6):762-770

Zhou F, Liu S, Hu Z, Kuang T, Paulsen H, Yang C (2009) Effect of monogalactosyldiacylglycerol on the interaction between photosystem II core complex and its antenna complexes in liposomes of thylakoid lipids. Photosynth Res 99:185-193. doi:10.1007/s11120-008-9388-9 


\section{Figure captions}

Fig. 1 Thin-layer chromatography of neutral lipids (A) and glycolipids (B). Sp: sample; Std: standard; TAG: triacylglycerols; GE: glyceril ethers; StE: sterols esters; Pg1 and Pg 2: unidentified pigmentary compounds 1 and 2; FFA: free fatty acids; NLx1 and 2: unidentified neutral lipids 1 and 2; ALK a and b: alkenones a and b; HC: hydrocarbons; MGDG: monogalactosylacylglycerol; SQDG:

sulfoquinovosylacylglycerol; DGDG: digalactosylacylglycerol; GLx1,2,: unidentified glycolipids 1 and 2.

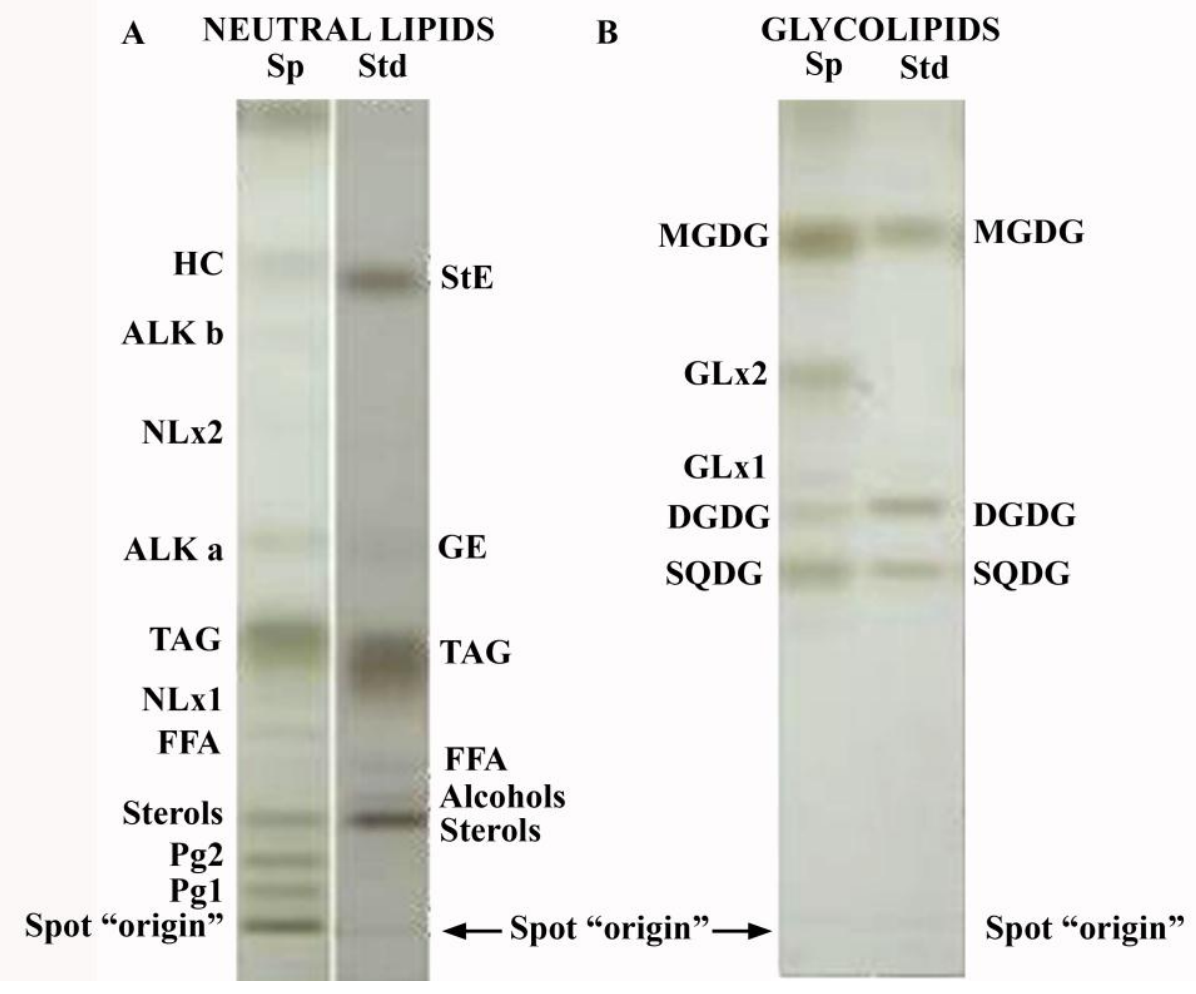


Fig. 2 Thin-layer chromatography (TLC) plate of a sample ( $\mathrm{Sp}$, left side) of Tisochrysis lutea phospholipids and the standards (std, right side). In both sides of the graphic the spectrum of bands after reading the plate at $370 \mathrm{~nm}$ can be seen. Identification of the different compounds could not be done due to the lack of correlation between samples and standards, i.e. bands of compounds of the standards were not aligned with those bands in the sample. The lack of identification of phospholipids in T. lutea hindered the study of biochemical composition of the structure of this species of microalgae.

LPC: lysophosphatidyl-choline; Sm: sphingomyelin; PC: phosphatidylcholine; PS: phosphatidylserine; PI: phosphatidylinositol; PE: phosphatidylethanolamine.
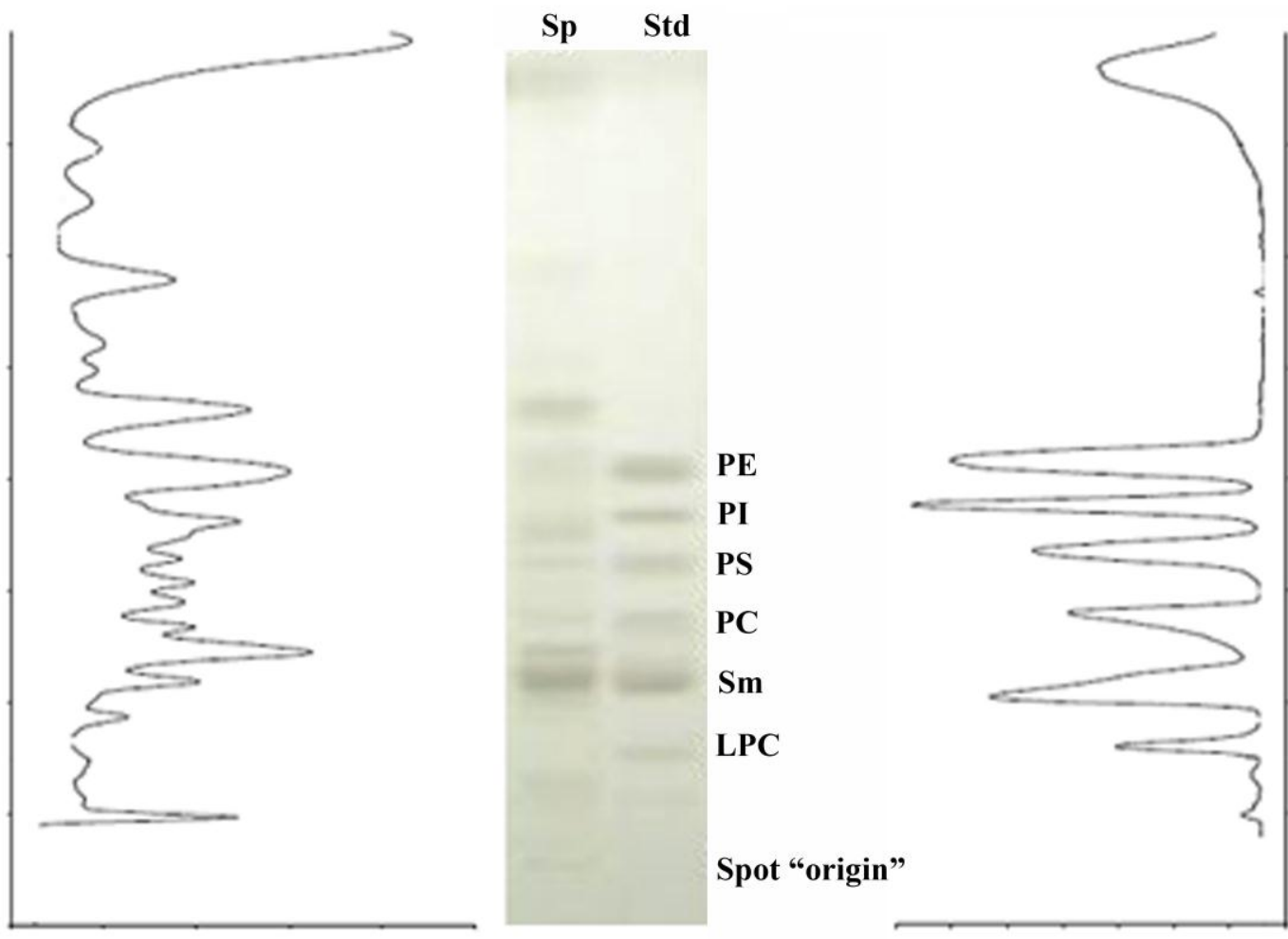

Fig. 3 Main fatty acids (expressed in weight $\%$ of total FA) contributing to the differences in fatty acid profile detected with SIMPER between Tisochrysis lutea grown in PBR at low $\left(D=0.2 \mathrm{~d}^{-1}\right)$ and high $\left(D=0.7 \mathrm{~d}^{-1}\right)$ dilution rate using pooled data (Mean \pm S.D., $\left.\mathrm{n}=6\right)$. A. Neutral lipids (NL). B. Glycolipids (GL). C. Polar lipids (PL). 

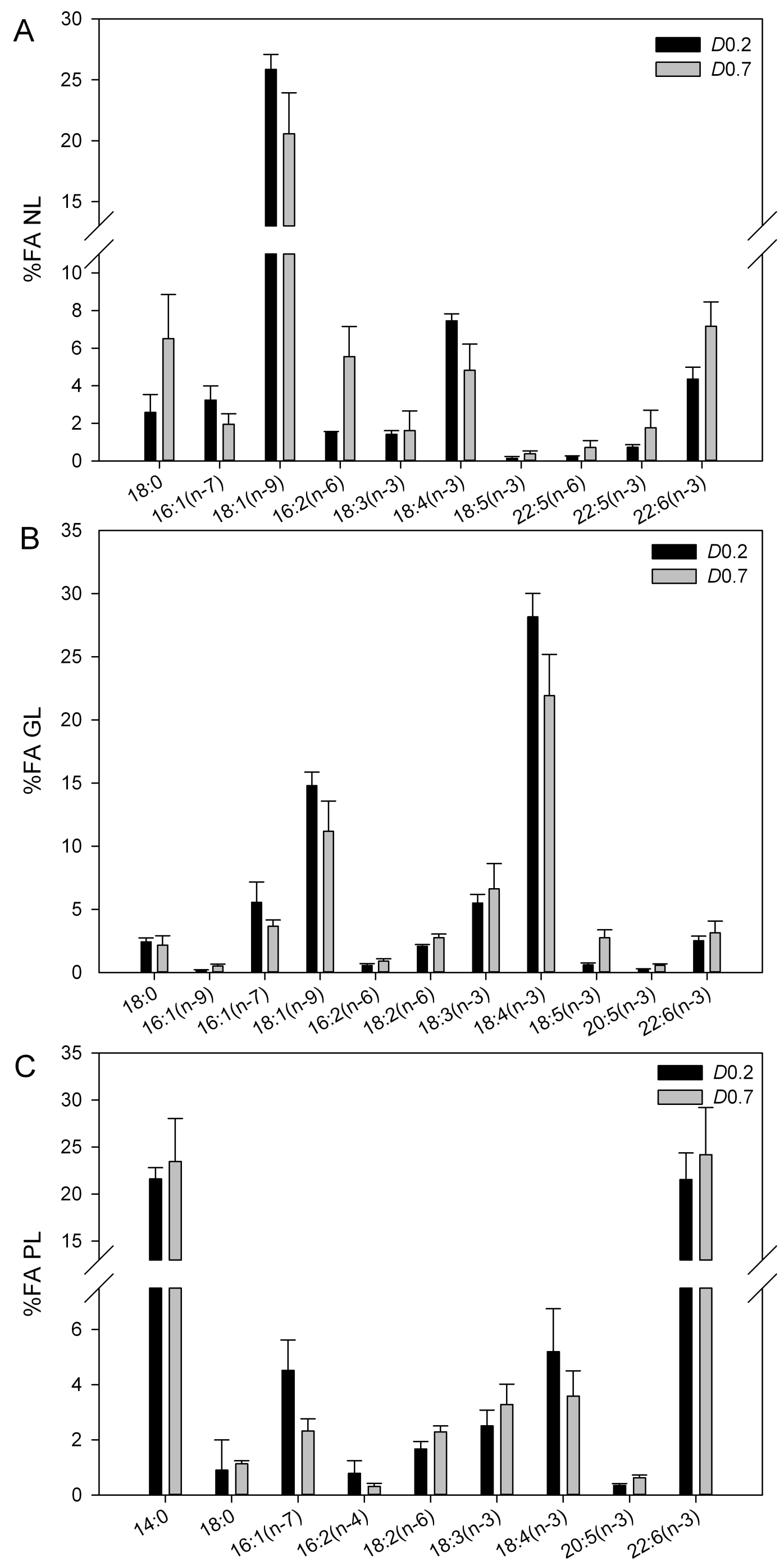
Table 1 Summary of the 2-way ANOVA performed on the proportion of neutral lipid classes of Tisochrysis lutea depending on dilution rate $(D)$ and light spectrum. Significant probabilities are in bold $(P<0.05)$. St: sterols; FFA: free fatty acids; $\mathrm{LNx}_{1}$ : unidentified neutral lipid 1; TAG: triacylglycerol; ALK a: alkenone a; $\mathrm{LNx}_{2}$ : unidentified neutral lipid 2; ALK b: alkenone b; HC: hydrocarbons. Mean not sharing a common superscript are significantly different $(P<0.05)$. ns: non-significant differences.

\begin{tabular}{|c|c|c|c|c|c|c|c|c|c|}
\hline $\bar{D}$ & Light & St & FFA & $\mathrm{NLx}_{1}$ & TAG & ALK a & $\mathrm{NLx}_{2}$ & ALK b & $\mathrm{HC}$ \\
\hline \multirow[t]{2}{*}{$\overline{0.2}$} & Blue & $14.8 \pm 1.3^{\mathrm{bc}}$ & $3.5 \pm 1.9^{b}$ & $5.7 \pm 0.7^{\mathrm{b}}$ & $54.9 \pm 0.7^{\mathrm{a}}$ & $5.5 \pm 1.1^{b c}$ & $3.1 \pm 0.6^{b}$ & $3.0 \pm 1.2^{\mathrm{ns}}$ & $9.4 \pm 3.6^{\mathrm{ab}}$ \\
\hline & White & $13.3 \pm 0.4^{\mathrm{c}}$ & $4.6 \pm 0.4^{\mathrm{b}}$ & $5.9 \pm 0.7^{b}$ & $50.5 \pm 0.6^{\mathrm{b}}$ & $6.8 \pm 0.2^{\mathrm{a}}$ & $2.6 \pm 0.2^{\mathrm{b}}$ & $3.6 \pm 0.4^{\text {ns }}$ & $12.8 \pm 0.4^{\mathrm{a}}$ \\
\hline \multirow[t]{2}{*}{0.7} & Blue & $18.6 \pm 0.9^{\mathrm{a}}$ & $9.0 \pm 2.4^{\mathrm{a}}$ & $9.3 \pm 1.2^{\mathrm{a}}$ & $41.2 \pm 2.4^{\mathrm{c}}$ & $4.7 \pm 0.4^{\mathrm{c}}$ & $6.8 \pm 1.8^{\mathrm{a}}$ & $4.4 \pm 0.8^{\mathrm{ns}}$ & $5.9 \pm 0.4^{\mathrm{b}}$ \\
\hline & White & $16.4 \pm$ & $5.2 \pm 1.2^{\mathrm{b}}$ & $7.6 \pm 0.6^{\mathrm{a}}$ & $49.0 \pm 3.6^{\mathrm{b}}$ & $6.0 \pm 0.4^{\mathrm{ab}}$ & $5.1 \pm 1.7^{\mathrm{a}}$ & $4.3 \pm 0.2^{\mathrm{ns}}$ & $6.3 \pm 0.8^{\mathrm{b}}$ \\
\hline \multicolumn{10}{|c|}{ Source of va } \\
\hline \multicolumn{2}{|c|}{ A: Lig } & & & & & & & & \\
\hline \multirow{2}{*}{\multicolumn{2}{|c|}{$\begin{array}{l}\text { B: } D \\
\mathrm{AB}\end{array}$}} & & & & & & & & \\
\hline & & 0.869 & 0.027 & 0.117 & 0.001 & 0.975 & 0.736 & 0.516 & 0.270 \\
\hline
\end{tabular}


Table 2 Summary of the 2-way ANOVA performed on the proportion of glycolipid classes of Tisochrysis lutea depending on dilution rate $(D)$ and light spectrum. Significant probabilities are in bold $(P<0.05)$. SQDG: sulfoquinovosylacylglycerol; DGDG: digalactosylacylglycerols; GLx 1,2 : unidentified glycolipids; MGDG: monogalactosylacylglycerols. Mean not sharing a common superscript are significantly different $(P<0.05)$. ns: non-significant differences.

\begin{tabular}{|c|c|c|c|c|c|c|}
\hline$D$ & Light & SQDG & DGDG & $\mathrm{GLx}_{1}$ & $\mathrm{GLx}_{2}$ & MGDG \\
\hline \multirow[t]{2}{*}{0.2} & Blue & $23.4 \pm 1.4^{\mathrm{b}}$ & $9.2 \pm 1.0^{\mathrm{a}}$ & $3.8 \pm 1.3^{b}$ & $18.7 \pm 1.8^{\text {ns }}$ & $44.8 \pm 3.1^{\mathrm{ns}}$ \\
\hline & White & $25.6 \pm 1.6^{\mathrm{ab}}$ & $6.1 \pm 2.0^{b}$ & $3.5 \pm 1.1^{b}$ & $18.4 \pm 0.7^{\mathrm{ns}}$ & $48.5 \pm 3.9^{\mathrm{ns}}$ \\
\hline \multirow[t]{2}{*}{0.7} & Blue & $30.8 \pm 3.4^{\mathrm{a}}$ & $1.7 \pm 0.3^{\mathrm{C}}$ & $4.0 \pm 1.4^{b}$ & $16.7 \pm 5.0^{\mathrm{ns}}$ & $47.4 \pm 8.5^{\mathrm{ns}}$ \\
\hline & White & $28.6 \pm 5.4^{\text {ab }}$ & $1.7 \pm 0.3^{\mathrm{C}}$ & $6.7 \pm 1.0^{\mathrm{a}}$ & $16.6 \pm 0.7^{\mathrm{ns}}$ & $46.5 \pm 5.3^{\mathrm{ns}}$ \\
\hline \multicolumn{7}{|c|}{ Source of variation } \\
\hline \multicolumn{2}{|c|}{ A: Light } & 0.998 & 0.011 & 0.170 & 0.964 & 0.686 \\
\hline \multicolumn{2}{|c|}{ B: $D$} & 0.028 & 0.000 & 0.065 & 0.235 & 0.933 \\
\hline \multicolumn{2}{|l|}{$\mathrm{AB}$} & 0.276 & 0.022 & 0.081 & 0.900 & 0.504 \\
\hline
\end{tabular}




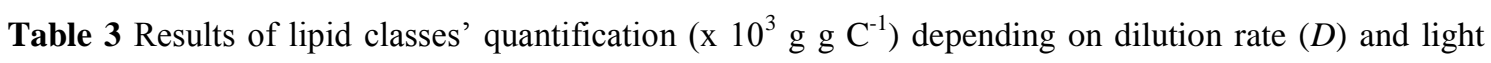
spectrum and summary of the 2 -way ANOVA results. Significant probabilities are in bold $(P<0.05)$. TAG: triacylglycerol; St: sterols; HC: hydrocarbons; MGDG: monogalactosylacylglycerols; DGDG: digalactosylacylglycerols. Mean not sharing a common superscript are significantly different $(P<0.05)$. ns: non-significant differences.

\begin{tabular}{llccccc}
\hline$D$ & Light & NL-TAG & NL-St & NL-HC & GL-MGDG & GL-DGDG \\
\hline 0.2 & Blue & $69.9 \pm 3.3^{\mathrm{a}}$ & $11.8 \pm 1.0^{\mathrm{a}}$ & $6.0 \pm 2.2^{\mathrm{b}}$ & $37.2 \pm 1.6^{\mathrm{ns}}$ & $17.8 \pm 0.5^{\mathrm{a}}$ \\
& White & $70.5 \pm 0.8^{\mathrm{a}}$ & $11.9 \pm 0.6^{\mathrm{a}}$ & $9.0 \pm 0.4^{\mathrm{a}}$ & $37.9 \pm 13.2^{\mathrm{ns}}$ & $11.2 \pm 0.2^{\mathrm{b}}$ \\
0.7 & Blue & $22.1 \pm 4.0^{\mathrm{b}}$ & $6.9 \pm 1.6^{\mathrm{b}}$ & $1.9 \pm 0.1^{\mathrm{c}}$ & $22.3 \pm 2.4^{\mathrm{ns}}$ & $10.6 \pm 2.1^{\mathrm{b}}$ \\
& White & $32.7 \pm 3.6^{\mathrm{b}}$ & $7.2 \pm 0.9^{\mathrm{b}}$ & $2.2 \pm 0.3^{\mathrm{c}}$ & $26.4 \pm 5.2^{\text {ns }}$ & $7.6 \pm 3.5^{\mathrm{b}}$ \\
\multicolumn{2}{l}{ Source de variation } & & & & & \\
\hline A: Light & 0.186 & 0.253 & $\mathbf{0 . 0 2 9}$ & 0.788 & 0.778 \\
B: $D$ & $\mathbf{0 . 0 0 6}$ & $\mathbf{0 . 0 4 0}$ & $\mathbf{0 . 0 0 1}$ & 0.218 & $\mathbf{0 . 0 3 6}$ \\
AB & 0.558 & 0.942 & 0.062 & 0.757 & $\mathbf{0 . 0 4 4}$ \\
\hline
\end{tabular}


Table 4 Fatty acid composition within lipid classes depending on dilution rate $\left(D, 0.2\right.$ or $\left.0.7 \mathrm{~d}^{-1}\right)$ and light spectrum (white and blue light) $\left(\mathrm{x} 10^{3} \mathrm{~g} \mathrm{~g} \mathrm{C} \mathrm{C}^{-1} \pm \mathrm{S} . \mathrm{D}\right.$., $\left.\mathrm{n}=3\right)$. NL:

Neutral lipids; GL: Glycolipids; PL: Phospholipids.

\begin{tabular}{|c|c|c|c|c|c|c|c|c|c|c|c|c|}
\hline & \multicolumn{6}{|c|}{$D=0.2 \mathrm{~d}^{-1}$} & \multicolumn{6}{|c|}{$D=0.7 \mathrm{~d}^{-1}$} \\
\hline & \multicolumn{3}{|c|}{ White } & \multicolumn{3}{|c|}{ Blue } & \multicolumn{3}{|c|}{ White } & \multicolumn{3}{|c|}{ Blue } \\
\hline & NL & GL & PL & $\mathrm{NL}$ & GL & PL & NL & GL & PL & $\mathrm{NL}$ & GL & PL \\
\hline $14: 0$ & $29.8 \pm 1.7$ & $26.1 \pm 0.6$ & $14.2 \pm 2.0$ & $29.7 \pm 0.9$ & $21.9 \pm 1.9$ & $18.8 \pm 2.5$ & $13.8 \pm 4.0$ & $24.7 \pm 3.7$ & $12.9 \pm 2.8$ & $15.9 \pm 0.7$ & $25.5 \pm 5.2$ & $13.1 \pm 6.2$ \\
\hline $16: 0$ & $16.2 \pm 1.1$ & $11.8 \pm 0.2$ & $12.4 \pm 1.0$ & $16.3 \pm 0.9$ & $10.4 \pm 1.1$ & $16.8 \pm 3.5$ & $7.3 \pm 2.6$ & $10.2 \pm 1.0$ & $10.7 \pm 1.1$ & $7.7 \pm 3.2$ & $9.3 \pm 0.6$ & $10.8 \pm 1.7$ \\
\hline 18:0 & $2.5 \pm 1.2$ & $2.2 \pm 0.3$ & $0.2 \pm 0.0$ & $2.5 \pm 1.0$ & $2.6 \pm 0.3$ & $1.4 \pm 0.9$ & $2.0 \pm 0.9$ & $1.8 \pm 0.4$ & $0.6 \pm 0.1$ & $3.6 \pm 2.2$ & $1.9 \pm 0.2$ & $0.6 \pm 0.2$ \\
\hline$\sum \mathrm{SFA}$ & $48.5 \pm 3.9$ & $40.2 \pm 0.6$ & $28.2 \pm 3.9$ & $48.5 \pm 1.1$ & $34.1 \pm 4.3$ & $37.0 \pm 5.1$ & $23.2 \pm 7.5$ & $36.7 \pm 4.3$ & $24.3 \pm 3.6$ & $27.2 \pm 4.7$ & $40.0 \pm 1.7$ & $24.5 \pm 8.0$ \\
\hline $16: 1(n-9)$ & $0.3 \pm 0.0$ & $0.2 \pm 0.0$ & $0.0 \pm 0.0$ & $0.3 \pm 0.0$ & $0.2 \pm 0.0$ & $0.1 \pm 0.0$ & $0.1 \pm 0.1$ & $0.5 \pm 0.0$ & $0.1 \pm 0.0$ & $0.2 \pm 0.1$ & $0.3 \pm 0.1$ & $0.1 \pm 0.0$ \\
\hline $16: 1(n-7)$ & $3.3 \pm 0.6$ & $7.0 \pm 0.6$ & $3.1 \pm 0.7$ & $2.8 \pm 0.8$ & $3.8 \pm 0.2$ & $3.8 \pm 2.2$ & $0.8 \pm 0.4$ & $3.0 \pm 0.5$ & $1.2 \pm 0.2$ & $1.5 \pm 0.5$ & $3.2 \pm 0.6$ & $1.4 \pm 0.7$ \\
\hline $18: 1(n-9)$ & $24.7 \pm 2.7$ & $14.5 \pm 1.1$ & $8.1 \pm 0.2$ & $24.7 \pm 0.9$ & $14.2 \pm 2.4$ & $10.6 \pm 4.1$ & $10.8 \pm 2.1$ & $9.0 \pm 1.1$ & $6.1 \pm 0.8$ & $9.3 \pm 0.7$ & $9.4 \pm 0.0$ & $6.6 \pm 1.2$ \\
\hline $18: 1(\mathrm{n}-7)$ & $0.6 \pm 0.2$ & $0.3 \pm 0.0$ & $1.6 \pm 0.2$ & $0.5 \pm 0.1$ & $0.5 \pm 0.0$ & $2.1 \pm 0.4$ & $0.3 \pm 0.1$ & $0.3 \pm 0.0$ & $1.3 \pm 0.2$ & $0.3 \pm 0.1$ & $0.3 \pm 0.0$ & $1.4 \pm 0.1$ \\
\hline$\sum$ MUFA & $28.8 \pm 2.5$ & $22.0 \pm 0.9$ & $13.7 \pm 1.4$ & $28.3 \pm 0.3$ & $18.7 \pm 2.3$ & $16.6 \pm 5.9$ & $12.0 \pm 2.7$ & $12.8 \pm 1.8$ & $8.7 \pm 0.9$ & $11.3 \pm 0.4$ & $13.6 \pm 0.2$ & $9.5 \pm 2.0$ \\
\hline $16: 2(n-6)$ & $1.4 \pm 0.1$ & $0.7 \pm 0.0$ & $0.0 \pm 0.0$ & $1.5 \pm 0.1$ & $0.4 \pm 0.1$ & $0.2 \pm 0.1$ & $1.8 \pm 0.0$ & $0.9 \pm 0.2$ & $0.2 \pm 0.0$ & $2.6 \pm 0.8$ & $0.7 \pm 0.3$ & $0.2 \pm 0.0$ \\
\hline $16: 2(n-4)$ & $0.2 \pm 0.0$ & $0.9 \pm 0.1$ & $0.7 \pm 0.1$ & $0.2 \pm 0.1$ & $0.6 \pm 0.0$ & $0.2 \pm 0.1$ & $0.0 \pm 0.0$ & $0.4 \pm 0.2$ & $0.1 \pm 0.0$ & $0.3 \pm 0.2$ & $0.4 \pm 0.0$ & $0.2 \pm 0.0$ \\
\hline $18: 2(\mathrm{n}-6)$ & $3.2 \pm 0.1$ & $2.1 \pm 0.2$ & $1.2 \pm 0.2$ & $3.1 \pm 0.1$ & $1.9 \pm 0.3$ & $1.3 \pm 0.6$ & $2.0 \pm 0.5$ & $2.2 \pm 0.4$ & $1.2 \pm 0.2$ & $2.0 \pm 0.0$ & $2.5 \pm 0.1$ & $1.4 \pm 0.2$ \\
\hline $18: 3(\mathrm{n}-3)$ & $1.4 \pm 0.3$ & $5.3 \pm 0.5$ & $1.5 \pm 0.3$ & $1.3 \pm 0.0$ & $5.3 \pm 0.3$ & $2.6 \pm 0.8$ & $0.5 \pm 0.4$ & $5.6 \pm 1.5$ & $1.8 \pm 0.6$ & $1.0 \pm 0.2$ & $5.9 \pm 0.2$ & $1.8 \pm 0.7$ \\
\hline $18: 4(n-6)$ & $0.6 \pm 0.1$ & $0.0 \pm 0.0$ & $0.0 \pm 0.0$ & $0.5 \pm 0.1$ & $0.0 \pm 0.0$ & $0.0 \pm 0.0$ & $0.2 \pm 0.1$ & $0.0 \pm 0.0$ & $0.0 \pm 0.0$ & $0.2 \pm 0.1$ & $0.0 \pm 0.0$ & $0.0 \pm 0.0$ \\
\hline $18: 4(n-3)$ & $6.7 \pm 0.5$ & $27.1 \pm 1.6$ & $3.0 \pm 0.7$ & $7.3 \pm 0.5$ & $27.5 \pm 4.1$ & $5.4 \pm 2.8$ & $2.3 \pm 1.3$ & $20.3 \pm 3.8$ & $2.1 \pm 0.5$ & $8.1 \pm 5.3$ & $22.2 \pm 1.1$ & $1.7 \pm 0.8$ \\
\hline $18: 5(n-3)$ & $0.1 \pm 0.0$ & $0.5 \pm 0.1$ & $0.1 \pm 0.0$ & $0.2 \pm 0.1$ & $0.4 \pm 0.3$ & $0.1 \pm 0.1$ & $0.2 \pm 0.1$ & $2.1 \pm 1.0$ & $0.1 \pm 0.1$ & $1.3 \pm 1.3$ & $3.1 \pm 0.3$ & $0.1 \pm 0.1$ \\
\hline $20: 4(n-6)$ & $0.6 \pm 0.2$ & $0.0 \pm 0.0$ & $0.1 \pm 0.0$ & $0.5 \pm 0.1$ & $0.0 \pm 0.0$ & $0.0 \pm 0.0$ & $0.4 \pm 0.1$ & $0.0 \pm 0.0$ & $0.0 \pm 0.0$ & $0.3 \pm 0.0$ & $0.0 \pm 0.0$ & $0.0 \pm 0.0$ \\
\hline $20: 5(n-3)$ & $0.3 \pm 0.1$ & $0.1 \pm 0.0$ & $0.3 \pm 0.0$ & $0.3 \pm 0.0$ & $0.3 \pm 0.0$ & $0.2 \pm 0.1$ & $0.1 \pm 0.1$ & $0.5 \pm 0.0$ & $0.3 \pm 0.1$ & $0.2 \pm 0.0$ & $0.4 \pm 0.0$ & $0.3 \pm 0.0$ \\
\hline $22: 5(n-6)$ & $0.2 \pm 0.0$ & $0.2 \pm 0.0$ & $0.1 \pm 0.0$ & $0.3 \pm 0.0$ & $0.2 \pm 0.0$ & $0.1 \pm 0.1$ & $0.2 \pm 0.1$ & $0.2 \pm 0.1$ & $0.3 \pm 0.0$ & $0.4 \pm 0.2$ & $0.2 \pm 0.0$ & $0.4 \pm 0.0$ \\
\hline $22: 5(n-3)$ & $0.7 \pm 0.2$ & $0.5 \pm 0.1$ & $2.7 \pm 0.2$ & $0.7 \pm 0.0$ & $0.5 \pm 0.1$ & $2.8 \pm 0.2$ & $0.6 \pm 0.1$ & $0.5 \pm 0.1$ & $1.9 \pm 0.5$ & $0.9 \pm 0.2$ & $0.5 \pm 0.2$ & $2.3 \pm 0.0$ \\
\hline $22: 6(n-3)$ & $4.0 \pm 1.0$ & $2.3 \pm 0.3$ & $14.7 \pm 0.7$ & $4.3 \pm 0.4$ & $2.6 \pm 0.5$ & $17.3 \pm 0.7$ & $2.9 \pm 0.7$ & $2.9 \pm 0.1$ & $12.5 \pm 2.7$ & $3.7 \pm 1.4$ & $2.4 \pm 0.4$ & $13.9 \pm 0.9$ \\
\hline$\sum$ PUFA & $17.2 \pm 2.0$ & $39.4 \pm 1.8$ & $25.4 \pm 0.7$ & $19.3 \pm 0.7$ & $39.6 \pm 4.8$ & $30.3 \pm 3.6$ & $11.1 \pm 3.2$ & $35.7 \pm 6.8$ & $20.7 \pm 2.3$ & $20.8 \pm 3.9$ & $38.5 \pm 1.0$ & $22.4 \pm 0.7$ \\
\hline$\sum \mathrm{n}-6$ & $6.0 \pm 0.5$ & $3.0 \pm 0.2$ & $4.3 \pm 0.7$ & $5.3 \pm 1.0$ & $2.5 \pm 0.4$ & $1.7 \pm 0.7$ & $4.5 \pm 0.7$ & $3.3 \pm 0.5$ & $1.7 \pm 0.2$ & $5.4 \pm 1.1$ & $3.7 \pm 0.2$ & $2.0 \pm 0.2$ \\
\hline$\sum \mathrm{n}-3$ & $11.0 \pm 2.5$ & $35.5 \pm 1.7$ & $20.1 \pm 1.3$ & $13.9 \pm 0.8$ & $36.5 \pm 4.4$ & $28.4 \pm 3.1$ & $6.6 \pm 2.5$ & $31.9 \pm 6.1$ & $18.8 \pm 2.1$ & $15.0 \pm 4.8$ & $34.5 \pm 0.8$ & $20.2 \pm 0.5$ \\
\hline$n-3 / n-6$ & $1.9 \pm 0.5$ & $12.1 \pm 0.8$ & $4.7 \pm 0.1$ & $2.7 \pm 0.6$ & $14.7 \pm 1.1$ & $18.1 \pm 5.4$ & $1.4 \pm 0.3$ & $9.6 \pm 0.4$ & $11.1 \pm 1.3$ & $2.9 \pm 1.5$ & $9.4 \pm 0.2$ & $10.3 \pm 0.8$ \\
\hline TOTAL & $94.5 \pm 5.6$ & $101.6 \pm 3.0$ & $67.5 \pm 6.7$ & $96.1 \pm 0.4$ & $92.3 \pm 11.2$ & $83.9 \pm 14.6$ & $46.3 \pm 13.3$ & $85.2 \pm 12.8$ & $53.7 \pm 4.1$ & $59.3 \pm 1.2$ & $92.1 \pm 2.9$ & $56.4 \pm 10.7$ \\
\hline
\end{tabular}


Table 5 Summary of the 2-way analysis of variance (ANOVA) results in each lipid class for total fatty acids and in total fatty acids (x $10^{3} \mathrm{~g} \mathrm{~g} \mathrm{C}^{-1}$ ), their classes (SFAs, MUFAs and PUFAs) and n-3 and n-6 depending on dilution rate $(D)$ and light spectrum. Significant probabilities are in bold $(P<0.05)$.

\begin{tabular}{|c|c|c|c|c|c|c|c|c|c|}
\hline & \multicolumn{9}{|c|}{ NL } \\
\hline Source of variation & Total & SFAs & MUFAs & PUFAs & $n-3$ & n-6 & $20: 4(n-6)$ & $20: 5(n-3)$ & $22: 6(n-3)$ \\
\hline A: Light & 0.319 & 0.591 & 0.896 & 0.112 & 0.170 & 0.361 & 0.630 & 0.144 & 0.503 \\
\hline B: $D$ & 0.009 & 0.014 & 0.002 & 0.325 & 0.516 & 0.216 & 0.004 & 0.030 & 0.669 \\
\hline \multirow[t]{2}{*}{$\mathrm{AB}$} & 0.518 & 0.767 & 0.601 & 0.159 & 0.214 & 0.664 & 0.073 & 0.505 & 0.803 \\
\hline & \multicolumn{9}{|c|}{ GL } \\
\hline Source of variation & Total & SFAs & MUFAs & PUFAs & n-3 & n-6 & $20: 4(n-6)$ & $20: 5(n-3)$ & $22: 6(n-3)$ \\
\hline A: Light & 0.986 & 0.699 & 0.214 & 0.534 & 0.444 & 0.662 & - & 0.914 & 0.624 \\
\hline B: $D$ & 0.269 & 0.650 & 0.006 & 0.490 & 0.379 & 0.067 & - & 0.000 & 0.653 \\
\hline \multirow[t]{2}{*}{$\mathrm{AB}$} & 0.341 & 0.141 & 0.099 & 0.884 & 0.991 & 0.191 & - & 0.002 & 0.303 \\
\hline & \multicolumn{9}{|c|}{ PL } \\
\hline Source of variation & Total & SFAs & MUFAs & PUFAs & $n-3$ & n-6 & $20: 4(n-6)$ & $20: 5(n-3)$ & $22: 6(n-3)$ \\
\hline A: Light & 0.172 & 0.299 & 0.346 & 0.035 & 0.005 & 0.009 & 0.000 & 0.751 & 0.019 \\
\hline B: $D$ & 0.021 & 0.080 & 0.025 & 0.004 & 0.006 & 0.007 & 0.000 & 0.043 & 0.007 \\
\hline $\mathrm{AB}$ & 0.370 & 0.268 & 0.690 & 0.523 & 0.053 & 0.003 & 0.000 & 0.307 & 0.931 \\
\hline
\end{tabular}

